\title{
A Theoretical Study of the Inversion and Rotation Barriers in Methyl-Substituted Amines
}

\author{
Júnior Nascimento, ${ }^{a}$ Marina Pelegrini, ${ }^{c}$ Luiz F. A. Ferrão, ${ }^{a, b}$ \\ Orlando Roberto-Neto ${ }^{d}$ and Francisco B. C. Machado ${ }^{* a}$
}

\begin{abstract}
${ }^{a}$ Departamento de Química and ${ }^{b}$ Departamento de Física, Instituto Tecnológico de Aeronáutica, 12228-900 São José dos Campos-SP, Brazil
\end{abstract}

'Divisão de Ensino, Academia da Força Aérea, 13643-000 Pirassununga-SP, Brazil

${ }^{d}$ Divisão de Aerotermodinâmica e Hipersônica, Instituto de Estudos Avançados, 12228-840 São José dos Campos-SP, Brazil

\begin{abstract}
Barreiras de energia para os movimentos de inversão e rotação das moléculas metilamina, dimetilamina e trimetilamina foram calculadas usando a metodologia CCSD(T)//B3LYP com os conjuntos de funções de base de Dunning, cc-pVTZ, cc-pVQZ e cc-pCVTZ. O procedimento de extrapolação para o conjunto de base completa (complete basis set, CBS) e os efeitos da correlação dos elétrons do caroço também foram incluídos nos cálculos das barreiras de energia. Nossos melhores resultados estão em excelente concordâncias com os dados experimentais, indicando que a metodologia utilizada é recomendada para a predição exata de propriedades estruturais e de barreiras de energia de outros sistemas moleculares.
\end{abstract}

Barrier heights of the internal rotation and inversion motions of methylamine, dimethylamine and trimethylamine molecules were calculated with the CCSD(T)//B3LYP methodology in combination with the cc-pVTZ, cc-pVQZ, and cc-pCVTZ basis sets of Dunning. The complete basis set (CBS) extrapolation procedure and core-valence (CV) correlation effects are also examined to the barrier heights. Our best estimate results (CCSD(T)/CBS+CV//B3LYP/cc-pVQZ) are in very good agreement with the experimental data, indicating the use of this methodology to provide accurate predictions of structures and barrier heights for other systems.

Keywords: energy barriers, methylamine, dimethylamine, trimethylamine, CCSD//B3LYP

\section{Introduction}

The methyl-substituted amines, methylamine $\left(\mathrm{CH}_{3} \mathrm{NH}_{2}\right)$, dimethylamine $\left[\left(\mathrm{CH}_{3}\right)_{2} \mathrm{NH}\right]$, and trimethylamine $\left[\left(\mathrm{CH}_{3}\right)_{3} \mathrm{~N}\right]$ form an interesting group of molecules which are important in organic syntheses and biological processes, as well as they are efficient corrosion inhibitors of aluminum. Beyond their technological importance, these species are rich in structural features presenting large amplitude internal motions, rotation of the methyl groups and internal inversion of the amino group.

Methylamine has been extensively studied by experimentalists in which its internal rotation and inversion barrier heights were determined using microwave (MW), infrared (IR) and electron diffraction (ED) experiments. ${ }^{1-7}$

*e-mail: fmachado@ita.br
Methylamine is considered a small molecule from the theoretical point of view, therefore it is appropriate to be studied using high level theoretical quantum chemical methodologies, having received many contributions..$^{7-14}$ Lee et $a l .{ }^{8}$ investigated the origin of the structural stability of methylamine concluding that the stereo electronic effect is the major interaction force affecting its stability. Csonka and Sztraka ${ }^{9}$ using density functional and post-HartreeFock methodologies showed that the density functional BP86/6-311G(d) method provides reliable results for geometry and vibrational frequencies, as compared with the experimental results. Smeyers and Villa ${ }^{10}$ discussed the influence of the zero-point energy correction to the rotation and inversion motions based on the MP2 results, and During and Zheng ${ }^{7}$ calculated these motions barriers using B3LYP and MP2 methods. Recently, we have examined the convergence of the geometries, harmonic vibrational 
frequencies, and the barrier heights of the internal rotation and inversion motions of methylamine using the CCSD(T) theory with a systematic improvement via cc-pVDZ, cc-pVTZ, cc-pVQZ, and cc-pCVTZ basis sets and also including the contribution of the inner-shell and valenceshell electrons. ${ }^{11}$ More recently, Levi et al. ${ }^{12}$ carried out accurate calculations of the vibrational frequencies, Kim and Zeroka ${ }^{13}$ presented new and important results concerning the inversion and rotational barriers and Ducati et al. ${ }^{14}$ calculated the rotational barrier.

Geometries, vibrational frequencies and the inversion and rotation barriers of dimethylamine have been determined both experimentally and theoretically. ${ }^{15-23}$ The experimental investigations were obtained using electron diffraction, ${ }^{15}$ microwave, ${ }^{16,17}$ and infrared and Raman ${ }^{18,19}$ spectra. Theoretically, the calculations have been carried out using ab initio methods up to MP4 level. ${ }^{20-23}$

The trimethylamine molecule has also received various experimental and theoretical studies. ${ }^{24-31}$ The experimental data of the geometry, vibrational frequencies and internalinversion and rotational barriers were obtained using microwave, ${ }^{24,26}$ infrared and Raman, ${ }^{25,27}$ techniques and employing analysis of the ultraviolet absorption and fluorescence spectra. ${ }^{28}$ Theoretical results were also obtained using ab initio methods up to MP4 level. ${ }^{29-31}$

It has been adequately demonstrated that a simultaneous consideration of basis set saturation and core correlation effects using coupled cluster method and extended basis set provide very accurate values of many molecular properties. ${ }^{32,33}$ Recently, using this methodology, we have investigated the geometries, harmonic vibrational frequencies, and the barrier heights of methylamine. ${ }^{11}$ In this work, we are concerned with the calculations of the internal and rotational barrier heights of the methylsubstituted amines, methylamine $\left(\mathrm{CH}_{3} \mathrm{NH}_{2}\right)$, dimethylamine $\left[\left(\mathrm{CH}_{3}\right)_{2} \mathrm{NH}\right]$, and trimethylamine $\left[\left(\mathrm{CH}_{3}\right)_{3} \mathrm{~N}\right]$.

\section{Methodology}

For all conformers, geometry optimizations were performed using the B3LYP exchange-correlation functional at the density functional theory level ${ }^{34,35}$ and the cc-pVQZ basis set of Dunning. ${ }^{36}$ Intrinsic reaction coordinate (IRC) ${ }^{37}$ calculations were carried out in order to verify the connections of the transition states to the equilibrium geometries, as already done for methylamine by Kim and Zeroka ${ }^{13}$ and for trimethylamine by Tanaka and Aida. ${ }^{31}$ Next, using these optimized geometries, the barrier heights of the internal rotation and inversion motion of the methyl-substituted amines were calculated using coupled cluster theory, including a perturbative treatment of the triple excitations $(\operatorname{CCSD}(\mathrm{T})) .{ }^{38}$ The correlation-consistent polarized-valence triple and quadruple basis sets of Dunning, ${ }^{36}$ named as cc-pVTZ, and cc-pVQZ, were employed. As it is well known, these basis set are built for frozen core electron calculations. The $\operatorname{CCSD}(\mathrm{T})$ total energies were extrapolated to the complete basis set (CBS) limit by using the extrapolation procedure of Halkier et al. ${ }^{39}$

$\mathrm{E}_{\mathrm{CBS}}=\left[\mathrm{E}(n) \times n^{3}\right]-\left[\mathrm{E}(n-1) \times(n-1)^{3}\right] / n^{3}-(n-1)^{3}$

where $n$ equals 4 for cc-pVQZ basis set. In order to provide the effect of core-valence correlation (CV) we have also used the correlation consistent core and valence polarization triple zeta basis set (cc-pCVTZ) of Woon and Dunning. ${ }^{40}$ Thus, these calculations were carried out correlating both the valence electrons and all electrons. Therefore, the barrier heights $(\Delta \mathrm{E})$ were calculated using the expression,

$\Delta \mathrm{E}=\left(\Delta \mathrm{E}_{\mathrm{CBS}}\right.$, valence $)+\Delta \mathrm{E}$ (cc-pCVTZ, all electrons $)-$ $\Delta \mathrm{E}$ (cc-pCVTZ, valence)

As stated above, for methylamine, we have recently used CCSD(T) to optimize the geometries for all conformers and to calculate inversion and rotational barrier heights. ${ }^{11}$ Kim and Zeroka have shown recently two transition state structures for the inversion mode, with one and two imaginary frequencies, respectively. ${ }^{13}$ In order to clarify the previous structures of the inversion motion, ${ }^{11}$ we have also re-optimized the structures of all methylamine conformers using the CCSD(T) methodology.

All the calculations were carried out using the Gaussian 03 code $^{41}$ and Molpro 2002.6. ${ }^{42}$

\section{Results and Discussion}

The B3LYP/cc-pVQZ optimized geometries of all methylamine conformers are presented in Figure 1, and in Figure 2 are showed the dimethylamine and trimethylamine conformers.

Methylamine has its ground state equilibrium geometry represented by a staggered conformation, and the eclipsed conformation corresponds to the transition state of the internal rotation due to the torsional motion of a methyl moiety along the $\mathrm{CN}$ axis. The wagging motions of the amine hydrogen atoms present two planar conformations, which are first-order and second-order inversion transition states, as also determined by Kim and Zeroka. ${ }^{13}$ All of them belong to the $\mathrm{C}_{\mathrm{s}}$ symmetry and are shown in Figure 1 . Recently, we have optimized the geometry of methylamine 


\begin{tabular}{|l|l|}
\hline Ground state & Rotation transition state (297i) \\
\hline First-order inversion transition state $(673 \mathrm{i})$ & Second-order inversion transition state $(112 \mathrm{i}, 660 \mathrm{i})$ \\
\hline
\end{tabular}

Figure 1. The conformation structures of methylamine. Values in brackets correspond to the imaginary frequencies (in $\left.\mathrm{cm}^{-1}\right) \mathrm{calculated}$ at B3LYP/ccpVQZ level.

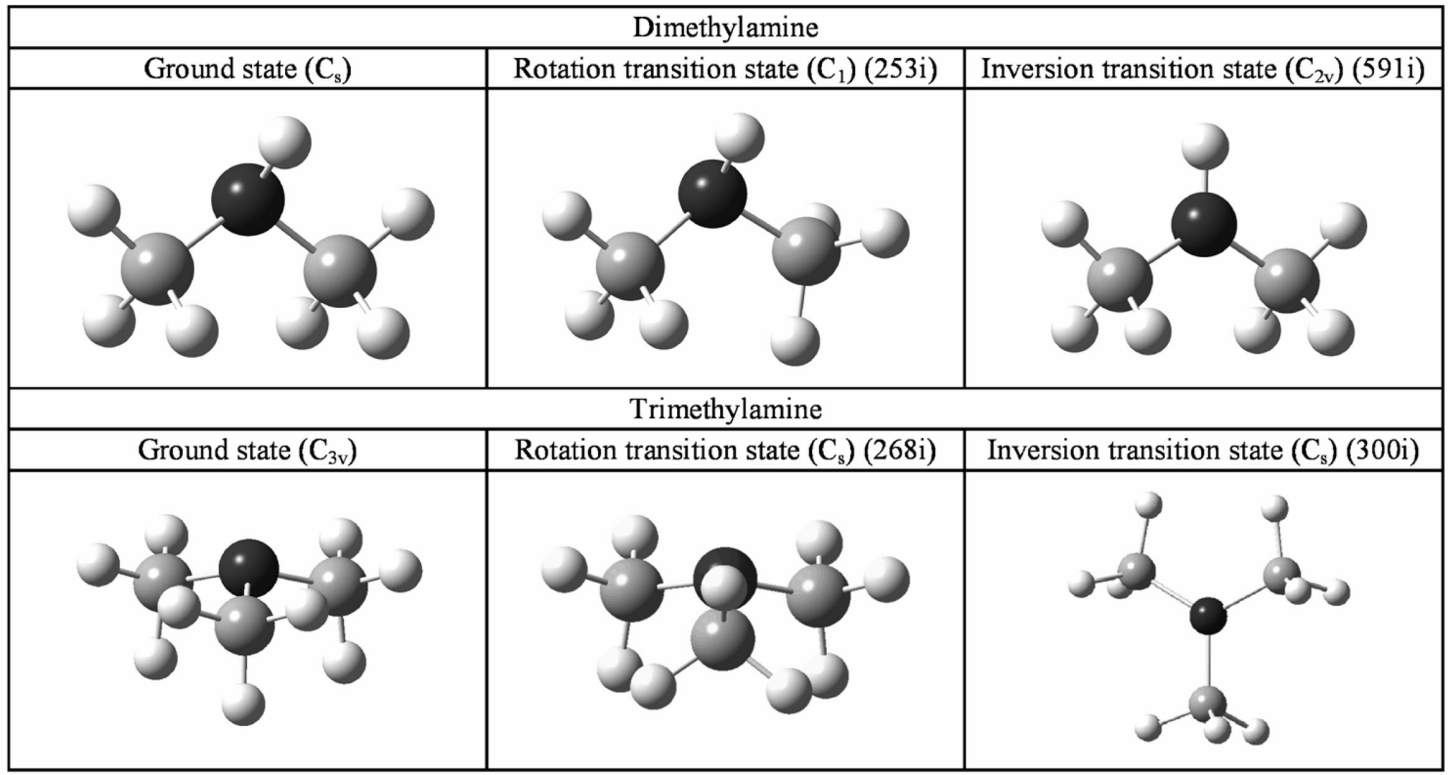

Figure 2. The conformation structures of dimethylamine and trimethylamine. Values in brackets correspond to the imaginary frequencies (in $\left.\mathrm{cm}^{-1}\right)$ calculated at B3LYP/cc-pVQZ level.

using the $\operatorname{CCSD}(\mathrm{T}) / \mathrm{CBS}$ methodology ${ }^{11}$ and, in this work, as discussed before, we have re-optimized the structures of all conformers using $\operatorname{CCSD}(\mathrm{T})$ methodology, in order to clarify the previous structures of the inversion motion. As one can see, the present results show that, in fact, the previous structures ${ }^{11}$ refer to the first-order inversion motion with one imaginary frequency. The imaginary frequencies calculated at the CCSD(T)/cc-pVTZ level are $749 \mathrm{i} \mathrm{cm}^{-1}$ for the first-order inversion structure, $166 \mathrm{i}$ and $740 \mathrm{i} \mathrm{cm}^{-1}$ for the second-order, and $317 \mathrm{i} \mathrm{cm}^{-1}$ for the rotation transition state. These imaginary frequencies calculated at B3LYP/ cc-pVQZ level, are respectively 673i, 112i and 660i, and $297 \mathrm{i} \mathrm{cm}^{-1}$ as reported in Figure 1. Note that the B3LYP imaginary frequencies differ no more than $80 \mathrm{~cm}^{-1}$ from the $\operatorname{CCSD}(\mathrm{T}) / \mathrm{cc}-\mathrm{pVTZ}$ results. All geometric parameters calculated using B3LYP/cc-pVQZ are, in general, in good agreement with the $\operatorname{CCSD}(\mathrm{T})$ results and also with previous theoretical calculations $\mathrm{s}^{7-10,13,14}$ and experimental data. ${ }^{2-4} \mathrm{We}$ have also carried out the IRC calculations using the B3LYP/ cc-pVTZ method and the results confirm that the first-order inversion transition state and the rotation transition state connect to the ground state, as already shown by Kim and Zeroka ${ }^{13}$ using a more complete two-dimensional potential energy surface. In this work, the IRC paths for the rotation motion were calculated by changing the dihedral angle (d) ( $\mathrm{H}-\mathrm{C}-\mathrm{N}$ lone-pair). The changes in the energy relative 


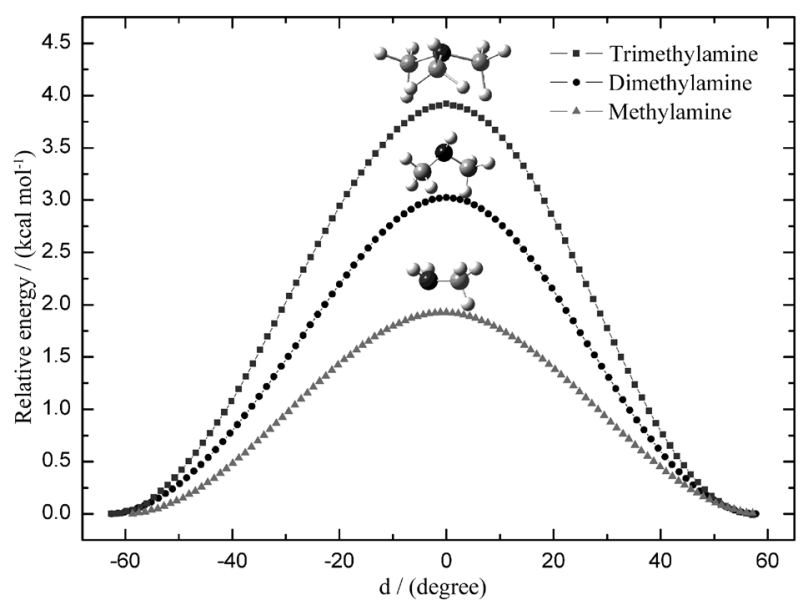

Figure 3. Potential energy curves (in $\mathrm{kcal} \mathrm{mol}^{-1}$ ) along the IRC path for the rotation motion at B3LYP/cc-pVTZ. The dihedral angle $(\mathrm{d})=-60^{\circ}$ and $60^{\circ}$ corresponds to the ground state of each molecule and $\mathrm{d}=0^{\circ}$ corresponds to the rotation transition state structures (showed).

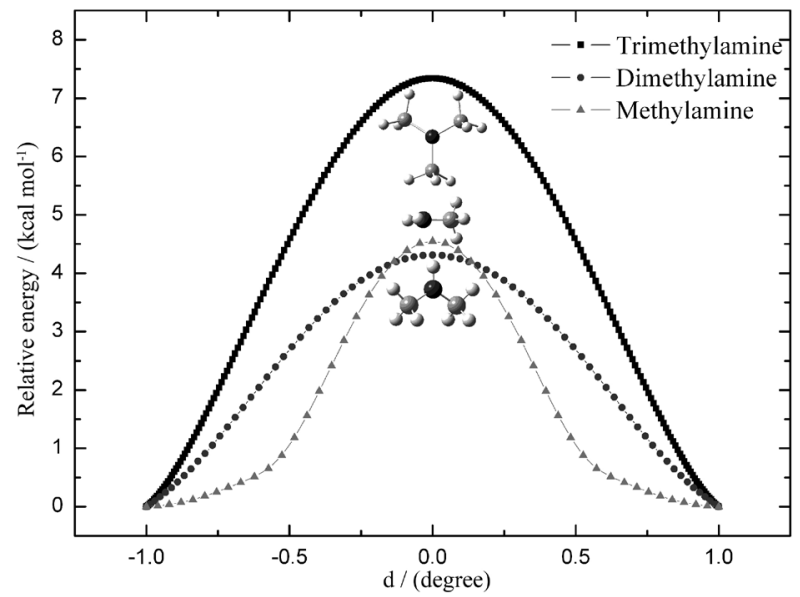

Figure 4. Potential energy curves (in $\mathrm{kcal} \mathrm{mol}^{-1}$ ) along the IRC path for the inversion motion at B3LYP/cc-pVTZ. The degree of inversion (d) for methylamine is defined in the text, for dimethylamine see Figure 5, and for trimethylamine see Figure 2 in reference $31 . \mathrm{d}=-1.0$ or 1.0 correspond to the ground state of each molecule and $d=0.0$ corresponds to the inversion transition state structures (showed).

to the ground state structure $\left(\mathrm{d}= \pm 60^{\circ}\right)$ are presented in Figure 3. The IRC calculations for the inversion motion are presented in Figure 4 that shows the potential energy as a function of the degree of inversion d, which is defined as:

$|\mathrm{d}|=\alpha / \alpha_{g s}$

where, $\alpha$ is the $\mathrm{H}-\mathrm{N}-\mathrm{C}-\mathrm{H}$ dihedral angle, which is $\pm 58.8^{\circ}$ at the ground state conformation $\left(\alpha_{\mathrm{gs}}\right)$ and equal to zero at the first-order inversion transition state geometry.

The origin of the structural stability was confirmed to be essentially due to the stereo electronic effect. As obtained by Lee et al. ${ }^{8}$ the change of rotational conformation energy $(\Delta \mathrm{E})$ and the change of the $\mathrm{C}-\mathrm{N}$ distance $\left(\Delta \mathrm{r}_{\mathrm{CN}}\right)$ varies almost linearly with either the cosine of the dihedral angle $\mathrm{d}(\mathrm{H}-\mathrm{C}-\mathrm{N}-$ lone-pair) or the cosine of $3 \mathrm{~d}$.

The two $\operatorname{CCSD}(\mathrm{T})$ results of the methylamine barrier heights, the single point calculations with the geometries optimized at the B3LYP/cc-pVQZ level and those obtained with the geometries optimized with the $\operatorname{CCSD}(\mathrm{T})$, are presented in Table 1. The results obtained with B3LYP/ccpVQZ and the experimental data ${ }^{1-3,5}$ are also presented. All the $\operatorname{CCSD}(\mathrm{T})$ results for barrier heights using the B3LYP/ cc-pVQZ optimized geometries are similar to the results calculated with the $\operatorname{CCSD}(\mathrm{T})$ geometries, differing no more than $0.08 \mathrm{kcal} \mathrm{mol}^{-1}$. It is important to mention that calculations of $T_{1}$ diagnostic were previously carried out ${ }^{11}$ at the CCSD/cc-pVQZ level with values equal to 0.008 for all conformations, which are small enough to allow the use of the single reference $\operatorname{CCSD}(\mathrm{T})$ wave functions in the study of the present molecular conformations. As already noticed ${ }^{11}$ the increase of the basis set and the inclusion of core correlation reduce both barrier height values, as also observed if one compares the CCSD(T)/cc-pVTZ result for the first-order rotation barrier with the one calculated by Ducati et al. ${ }^{14}$ with $\operatorname{CCSD}(\mathrm{T}) /$ aug-cc-pVTZ. The inclusion of ZPE correction decreases the values of barrier heights underestimating the CBS-DT (CBS extrapolation using double and triple basis set) results compared to the experimental data. The experimental rotation barriers range from $1.96^{2,3}$ to $2.05^{5} \mathrm{kcal} \mathrm{mol}^{-1}$, and for inversion, from $4.83^{1}$ to $5.56^{5} \mathrm{kcal} \mathrm{mol}^{-1}$. The $\operatorname{CCSD}(\mathrm{T})$ results with the CBS extrapolation and core-valence correlation corrections (CV) (equation 2), but without ZPE correction, are 1.83 and $4.99 \mathrm{kcal} \mathrm{mol}^{-1}$ for the rotation and inversion barriers. However, the CCSD(T)/cc-pVQZ (valence) results, without ZPE correction are 1.95 and $5.61 \mathrm{kcal} \mathrm{mol}^{-1}$, respectively. As one can see, the inclusion of the ZPE correction from the B3LYP/cc-pVQZ or from the CCSD(T)/CBS-DT calculations provide barrier height values lower than the experimental data, which are accurate enough to encourage us in using this methodology in the calculation of larger systems as dimethyl and trimethyl amines. Also, as affirmed above, the $\operatorname{CCSD}(\mathrm{T})$ and $\operatorname{CCSD}(\mathrm{T}) / / \mathrm{B} 3 \mathrm{LYP}$ barrier height results differ no more than $0.08 \mathrm{kcal} \mathrm{mol}^{-1}$ without ZPE. Including the B3LYP/cc-pVQZ ZPE correction in the single point $\operatorname{CCSD}(\mathrm{T})$ calculations, the difference from the optimized $\operatorname{CCSD}(\mathrm{T})$ result is not higher than $0.14 \mathrm{kcal} \mathrm{mol}^{-1}$. Therefore, the $\operatorname{CCSD}(\mathrm{T})$ single point calculations are reliable enough to calculate barrier heights for similar structures, and in this work, were carried out for the larger systems.

The B3LYP/cc-pVQZ dimethylamine conformation structures are presented in Figure 2. The ground state equilibrium geometry has a pyramidal structure with $\mathrm{C}_{\mathrm{s}}$ 
Table 1. Ground state total energy (in a.u.), internal rotation and inversion barrier heights (in kcal mol ${ }^{-1}$ ) of methylamine

\begin{tabular}{|c|c|c|c|c|}
\hline Methods & Ground state total energy & $\begin{array}{c}\text { First-order } \\
\text { Rotation }(\Delta \mathrm{E})\end{array}$ & $\begin{array}{c}\text { First-order } \\
\text { Inversion }(\Delta E)\end{array}$ & $\begin{array}{l}\text { Second-order } \\
\text { Inversion }(\Delta \mathrm{E})\end{array}$ \\
\hline B3LYP/cc-pVQZ & -95.90917 & $1.86(1.50)^{\mathrm{a}}$ & $4.57(3.41)^{\mathrm{a}}$ & $4.62(3.32)^{\mathrm{a}}$ \\
\hline $\operatorname{CCSD}(\mathrm{T}) / \mathrm{cc}-\mathrm{pVDZ}$ (valence) & $-95.86989^{c}$ & $2.75^{\mathrm{c}}(2.19)^{\mathrm{a}, \mathrm{c}}$ & $8.16^{\mathrm{c}}(6.95)^{\mathrm{a}, \mathrm{c}}$ & $8.24^{\mathrm{c}}(6.87)^{\mathrm{a}, \mathrm{c}}$ \\
\hline $\operatorname{CCSD}(\mathrm{T}) / \mathrm{cc}-\mathrm{pVTZ}$ (valence) & $\begin{array}{l}-95.96591^{\mathrm{b}} \\
-95.96673^{\mathrm{c}}\end{array}$ & $\begin{array}{c}2.09^{\mathrm{b}} \\
2.10^{\mathrm{c}}(1.72)^{\mathrm{a}, \mathrm{c}}\end{array}$ & $\begin{array}{c}6.11^{\mathrm{b}} \\
6.19^{\mathrm{c}}(5.09)^{\mathrm{a}, \mathrm{c}}\end{array}$ & $\begin{array}{c}6.17^{\mathrm{b}} \\
6.25^{\mathrm{c}}(4.99)^{\mathrm{a}, \mathrm{c}}\end{array}$ \\
\hline $\operatorname{CCSD}(\mathrm{T}) / \mathrm{cc}-\mathrm{pVQZ}$ (valence) & $\begin{array}{l}-95.72775^{\mathrm{b}} \\
-95.72781^{\mathrm{c}}\end{array}$ & $\begin{array}{l}1.96^{\mathrm{b}} \\
1.95^{\mathrm{c}}\end{array}$ & $\begin{array}{l}5.53^{\mathrm{b}} \\
5.56^{\mathrm{c}}\end{array}$ & $\begin{array}{l}5.58^{\mathrm{b}} \\
5.61^{\mathrm{c}}\end{array}$ \\
\hline CBS -DT (valence) (equation 1) & $-95.74293^{c}$ & $1.83^{\mathrm{c}}(1.52)^{\mathrm{a}, \mathrm{c}}$ & $5.36^{\mathrm{c}}(4.31)^{\mathrm{a}, \mathrm{c}}$ & $5.41^{\mathrm{c}}(4.20)^{\mathrm{a}, \mathrm{c}}$ \\
\hline CBS -TQ (valence) (equation 1) & $\begin{array}{l}-95.75050^{\mathrm{b}} \\
-95.75049^{\mathrm{c}}\end{array}$ & $\begin{array}{l}1.86^{\mathrm{b}} \\
1.85^{\mathrm{c}}\end{array}$ & $\begin{array}{l}5.11^{\mathrm{b}} \\
5.10^{\mathrm{c}}\end{array}$ & $\begin{array}{l}5.15^{\mathrm{b}} \\
5.14^{\mathrm{c}}\end{array}$ \\
\hline CCSD(T)/cc-pCVTZ (valence) & $\begin{array}{l}-95.69970^{\mathrm{b}} \\
-95.69984^{\mathrm{c}}\end{array}$ & $\begin{array}{l}2.07^{\mathrm{b}} \\
2.08^{\mathrm{c}}\end{array}$ & $\begin{array}{l}6.13^{\mathrm{b}} \\
6.21^{\mathrm{c}}\end{array}$ & $\begin{array}{l}6.18^{\mathrm{b}} \\
6.26^{\mathrm{c}}\end{array}$ \\
\hline CCSD(T)/cc-pCVTZ (full) & $\begin{array}{l}-95.80144^{\mathrm{b}} \\
-95.80155^{\mathrm{c}}\end{array}$ & $\begin{array}{l}2.06^{\mathrm{b}} \\
2.07^{\mathrm{c}}\end{array}$ & $\begin{array}{l}5.99^{\mathrm{b}} \\
6.05^{\mathrm{c}}\end{array}$ & $\begin{array}{l}6.04^{\mathrm{b}} \\
6.10^{\mathrm{c}}\end{array}$ \\
\hline$\Delta \mathrm{E}(\mathrm{CCSD}(\mathrm{T}) /$ equation 2$)$ & $\begin{array}{l}-95.85224^{\mathrm{b}} \\
-95.85221^{\mathrm{c}}\end{array}$ & $\begin{array}{l}1.85^{\mathrm{b}} \\
1.83^{\mathrm{c}}\end{array}$ & $\begin{array}{l}4.97^{\mathrm{b}} \\
4.94^{\mathrm{c}}\end{array}$ & $\begin{array}{l}5.02^{b} \\
4.99^{c}\end{array}$ \\
\hline Experimental & & $1.96^{\mathrm{d}}, 2.05^{\mathrm{e}}$ & & $4.83^{\mathrm{f}}, 5.56^{\mathrm{e}}$ \\
\hline
\end{tabular}

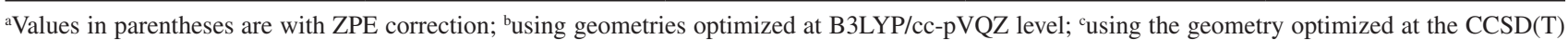
level; ${ }^{\mathrm{d}}$ references 2 and 3 ; ${ }^{\mathrm{e}}$ reference 5 ; ${ }^{\mathrm{f}}$ reference 1.

point group symmetry, and it will be denoted as the eclipsed conformation. The internal rotation of the methyl groups with $\mathrm{C}_{1}$ point group symmetry has a staggered conformation, and the inversion motion of the amine hydrogen has a planar conformation within $\mathrm{C}_{2 \mathrm{v}}$ point group symmetry. As obtained to methylamine, all geometrical parameters are in good agreement with previous experimental ${ }^{15,16}$ and theoretical results. ${ }^{21-23}$ In the planar structure, the $\mathrm{H}-\mathrm{C}-$ $\mathrm{N}-\mathrm{C}-\mathrm{H}$ atoms are coplanar to the amine hydrogen atom, and in the ground state pyramidal structure, this amine hydrogen atom forms an angle of 53.4 degrees to the $\mathrm{H}-\mathrm{C}-\mathrm{N}-\mathrm{C}-\mathrm{H}$ plane. These results are in good agreement with the MP2/6-31G $(\mathrm{d}, \mathrm{p})$ value, equal to 55.2 degrees, and also with the experimental data of 54.6 degrees. ${ }^{16}$ The IRC paths using the B3LYP/cc-pVTZ method for the rotation motion were calculated by changing the dihedral angle (d) $(\mathrm{H}-\mathrm{C}-\mathrm{N}-\mathrm{H})$. As calculated for methylamine, the changes in energy relative to the ground state structure $\left(\mathrm{d}= \pm 60^{\circ}\right)$ are presented in Figure 3. For the inversion the degree of inversion $d$ is defined as shown in Figure 5 and the IRC path is presented in Figure 4.

As analyzed for methylamine, the change of rotational conformation energy $(\Delta \mathrm{E})$ and the change of the $\mathrm{C}-\mathrm{N}$ distance $\left(\Delta \mathrm{r}_{\mathrm{CN}}\right)$ varies almost linearly with either the cosine of the dihedral angle $\mathrm{d}(\mathrm{H}-\mathrm{C}-\mathrm{N}$-lone-pair) or the cosine of $3 \mathrm{~d}$. Thus, we also concluded that the origin of the structural stability is due to the stereoelectronic effect.

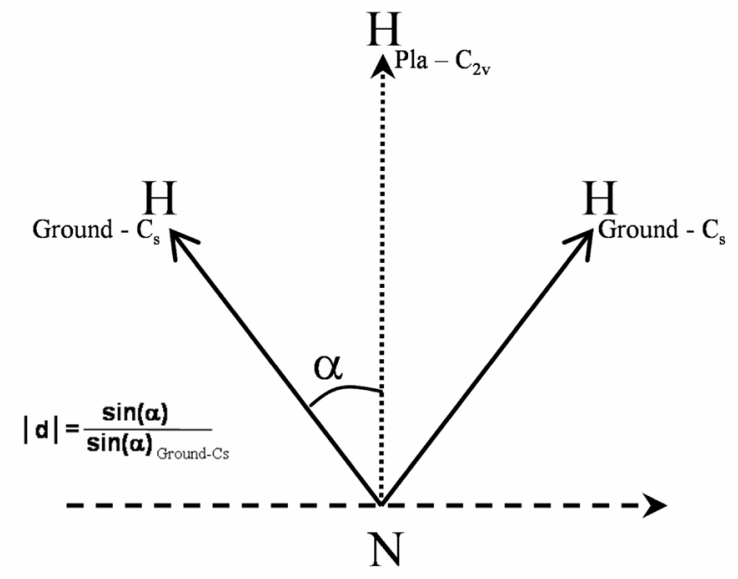

Figure 5. Definition of the degree of inversion $(d)$ in dimethylamine molecule: The $\mathrm{N}-\mathrm{H}$ vector is directed to $\mathrm{N}-\mathrm{H}$ bond. In the planar (inversion transition state) structure the $\mathrm{H}-\mathrm{C}-\mathrm{N}-\mathrm{C}-\mathrm{H}$ atoms are coplanar to the hydrogen amine atom $(\alpha=0)$, and in the ground state pyramidal structure this hydrogen amine atom forms an angle of 53.4 degrees to the $\mathrm{H}-\mathrm{C}-\mathrm{N}-\mathrm{C}-\mathrm{H}$ plane $\left(\sin \alpha=\sin \alpha_{\text {ground-Cs }}\right)$.

The dimethylamine barrier heights are calculated at the $\operatorname{CCSD}(\mathrm{T})$ level using the geometries optimized with B3LYP/cc-pVQZ and are presented in Table 2 together with the experimental data. ${ }^{16-19}$ As already discussed for the methylamine, the increase of the basis set and the inclusion of the core correlation reduce both barrier height values. The inclusion of core correlation is more important for the inversion barrier. For the internal rotation barrier, our 
Table 2. Internal rotation and inversion barrier heights (in $\mathrm{kcal} \mathrm{mol}^{-1}$ ) of dimethylamine. The CCSD(T) results are calculated using the B3LYP/cc-pVQZ optimized geometries

\begin{tabular}{lcc}
\hline Methods & Internal rotation $(\Delta \mathrm{E})$ & Inversion $(\Delta \mathrm{E})$ \\
\hline B3LYP/cc-pVQZ & $2.99(2.67)^{\mathrm{a}}$ & $4.23(3.24)^{\mathrm{a}}$ \\
CCSD(T)/cc-pVTZ (valence) & $3.20(2.88)$ & $6.13(5.14)$ \\
CCSD(T)/cc-pVQZ (valence) & $3.15(2.83)$ & $5.62(4.63)$ \\
CBS (valence) (equation 1) & $3.11(2.79)$ & $5.24(4.25)$ \\
CCSD(T)/cc-pCVTZ (valence) & $3.20(2.88)$ & $6.14(5.15)$ \\
CCSD(T)/cc-pCVTZ (full) & $3.20(2.88)$ & $6.01(5.02)$ \\
$\Delta \mathrm{E}(\mathrm{CCSD}(\mathrm{T}) /$ equation 2) & $3.11(2.79)$ & $5.11(4.12)$ \\
Theoretical & $3.43^{\mathrm{c}}$ & $6.60^{\mathrm{d}} ; 6.29^{\mathrm{e}}$ \\
Experimental & $3.013^{\mathrm{f}} ; 3.029^{\mathrm{g}}$ & $4.4^{\mathrm{h}}$ \\
\hline
\end{tabular}

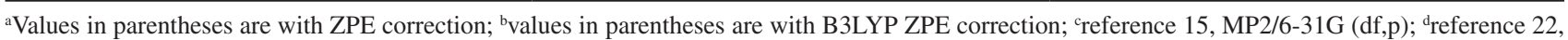

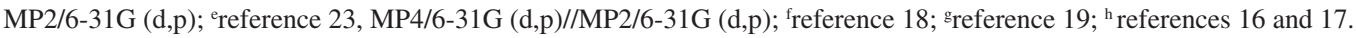

best result obtained at the $\mathrm{CCSD}(\mathrm{T}) / \mathrm{CBS}+\mathrm{CV} / / \mathrm{B} 3 \mathrm{LYP} /$ cc-pVQZ level (equation 2), is $3.11 \mathrm{kcal} \mathrm{mol}^{-1}$, which include the CBS and core-valence correlation effects. The previous theoretical result ${ }^{15}$ at MP2/6-31G(df,p) level is $3.43 \mathrm{kcal} \mathrm{mol}^{-1}$ and our B3LYP/cc-pVQZ result is $2.99 \mathrm{kcal} \mathrm{mol}^{-1}$. The experimental infrared and Raman data are respectively $3.013^{18}$ and $3.029^{19} \mathrm{kcal} \mathrm{mol}^{-1}$. Using $\mathrm{ZPE}$ correction, the B3LYP/cc-pVQZ result is 2.67 , which is relatively small compared to the experimental data. Using B3LYP ZPE corrections in the CCSD(T)/equation 2 and $\operatorname{CCSD}(\mathrm{T}) / \mathrm{cc}-\mathrm{pVQZ}$ results, the rotation barrier are 2.79 and $2.83 \mathrm{kcal} \mathrm{mol}^{-1}$, respectively. For the inversion, our best results using equation 2 and cc-pVQZ basis set are 5.11 and $5.62 \mathrm{kcal} \mathrm{mol}^{-1}$, respectively. The B3LYP/ccpVQZ is $4.23 \mathrm{kcal} \mathrm{mol}^{-1}$ and previous theoretical results using MP2/6-31G (d,p) and MP4/6-31G(d,p)//MP2/6-31G $(\mathrm{d}, \mathrm{p})$ are respectively 6.60 and $6.29 \mathrm{kcal} \mathrm{mol}^{-1} .{ }^{22,23}$ The experimental result obtained from microwave spectra is $4.4 \pm 1 \mathrm{kcal} \mathrm{mol}^{-1},{ }^{16,17}$ which has an error limit somewhat large. A better comparison with the experimental data should include the ZPE correction obtained from the B3LYP/cc-pVQZ calculations, which are 3.24, 4.12 and $4.63 \mathrm{kcal} \mathrm{mol}^{-1}$ calculated using B3LYP/ cc-pVQZ, CCSD(T)/equation 2 and CCSD(T)/cc-pVQZ, respectively.

Trimethylamine has its ground state equilibrium geometry well determined ${ }^{24,26,29-31}$ as a pyramidal structure with $\mathrm{C}_{3 \mathrm{v}}$ point group symmetry with an eclipsed conformation. Figure 2 gives the $\mathrm{C}_{3 \mathrm{v}}$ equilibrium geometry and the two other conformations with $\mathrm{C}_{\mathrm{s}}$ point group symmetry, the staggered and planar structures, which correspond respectively to the internal rotation of the methyl groups and to the skeletal inversion. All geometries were optimized using the B3LYP/cc-pVQZ method. The geometrical parameters, in general, are in good agreement with previous experimental $1^{24,26,27}$ and theoretical results. ${ }^{29,30}$ The IRC paths using the B3LYP/ cc-pVTZ method for the rotation motion were calculated by changing the dihedral angle $\mathrm{d}(\mathrm{H}-\mathrm{C}-\mathrm{N}-$ lone pair) and the relative energy from the ground state structure $\left(\mathrm{d}= \pm 60^{\circ}\right)$, which are presented in Figure 3. For the inversion, the IRC path is presented in Figure 4. The calculations were carried out using the degree of inversion d, as defined by Tanaka and Aida. ${ }^{31}$ As analyzed for methylamine and dimethylamine, the structural stability is essentially due to the stereo electronic effect.

Calculated trimethylamine barrier heights are presented in Table 3 together with the experimental data. ${ }^{24,25,27,28}$ The inclusion of core correlation is more important for the inversion barrier, as already discussed for the methylamine and dimethylamine. The calculated barrier height results for the torsion of one methyl group are consistent with the experimental and previous theoretical results. The B3LYP/ cc-pVQZ result without ZPE correction is $3.91 \mathrm{kcal} \mathrm{mol}^{-1}$ and the result with ZPE is $3.54 \mathrm{kcal} \mathrm{mol}^{-1}$, which seems underestimated compared to the experimental data, i.e., $4.40,{ }^{24} 4.06^{25}$ or $3.63^{27} \mathrm{kcal} \mathrm{mol}^{-1}$, as also observed to methylamine and dimethylamine. Our best result (equation 2) is $4.27 \mathrm{kcal} \mathrm{mol}^{-1}$, but if one uses the ZPE correction from the B3LYP/cc-pVQZ calculations, this value becomes $3.90 \mathrm{kcal} \mathrm{mol}^{-1}$. The previous MP4(SDQ)/ aug-cc-pVTZ result without ZPE is $4.04 \mathrm{kcal} \mathrm{mol}^{-1}{ }^{31}$ For the inversion, the B3LYP/cc-pVQZ without and with ZPE are 7.45 and $6.29 \mathrm{kcal} \mathrm{mol}^{-1}$, respectively. Our best result without ZPE is $9.51 \mathrm{kcal} \mathrm{mol}^{-1}$, which is similar to the previous theoretical study at MP4(SDQ)/aug-cc-pVTZ level, equal to $9.42 \mathrm{kcal} \mathrm{mol}^{-1} .{ }^{31}$ Using the ZPE correction from the B3LYP/cc-pVQZ calculations, our best result is $8.35 \mathrm{kcal} \mathrm{mol}^{-1}$, which is in very close agreement with the experimental value of $8.29 \mathrm{kcal} \mathrm{mol}^{-1} .28$ 
Table 3. Internal rotation and inversion barrier heights (in $\mathrm{kcal} \mathrm{mol}^{-1}$ ) of trimethylamine. The CCSD(T) results are calculated using the B3LYP/cc-pVQZ optimized geometries

\begin{tabular}{lcc}
\hline Methods & Internal rotation $(\Delta \mathrm{E})$ & Inversion $(\Delta \mathrm{E})$ \\
\hline B3LYP /cc-pVQZ & $3.91(3.54)^{\mathrm{a}}$ & $7.45(6.29)^{\mathrm{a}}$ \\
CCSD(T)/cc-pVTZ (valence) & $4.26(3.89)$ & $9.70(8.54)$ \\
CCSD(T)/cc-pVQZ (valence) & $4.27(3.90)$ & $9.65(8.49)$ \\
CBS (valence) (equation 1) & $4.27(3.90)$ & $9.61(8.45)$ \\
CCSD(T)/cc-pCVTZ (valence) & $4.28(3.91)$ & $9.73(8.57)$ \\
CCSD(T)/cc-pCVTZ (full) & $4.28(3.91)$ & $9.63(8.47)$ \\
$\Delta$ E (equation 2) & $4.27(3.90)$ & $9.51(8.35)$ \\
Theoretical & $4.04^{\mathrm{c}}$ & $9.42^{\mathrm{c}}$ \\
Experimental & $4.40^{\mathrm{d} ;} 4.06^{\mathrm{e}} ; 3.63^{\mathrm{f}}$ & $8.29^{\mathrm{g}}$ \\
\hline
\end{tabular}

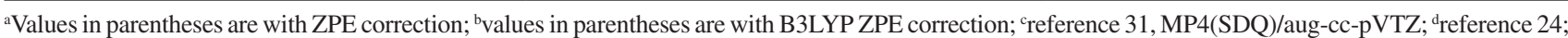
${ }^{\mathrm{e}}$ reference 25 ; ${ }^{\mathrm{f}}$ reference 27 ; ${ }^{\mathrm{g}}$ reference 28.

\section{Conclusions}

In this work, we have used the cc-pVTZ, cc-pVQZ, and cc-pCVTZ basis sets of Dunning and the CCSD(T) theory in order to obtain accurate values of inversion and rotation barrier heights of the methylamine, dimethylamine and trimethylamine molecules using the optimized geometries and frequencies calculated at B3LYP/cc-pVQZ level. CBS extrapolation procedure and core-valence correlation effects are also employed in the calculations of the barrier heights using $\operatorname{CCSD}(\mathrm{T})$ single point calculations. Our best estimate results (equation 2) are in very good agreement with the experimental data. Therefore, the methodology, $\operatorname{CCSD}(\mathrm{T}) /$ $\mathrm{CBS}+\mathrm{CV} / / \mathrm{B} 3 \mathrm{LYP} / \mathrm{cc}-\mathrm{pVQZ}$, used in this study provides accurate and consistent predictions of structures and barrier height values of internal motions in methyl substituted amines, and it is also recommended to be applied to other systems.

\section{Supplementary Information}

Supplementary information is available free of charge at http://jbcs.sbq.org.br as a PDF file.

\section{Acknowledgments}

The authors acknowledge the continuous research and the fellowship support of the Conselho Nacional de Desenvolvimento Científico e Tecnológico (CNPq) and the Fundação de Amparo à Pesquisa do Estado de São Paulo (FAPESP).

\section{References}

1. Tsuboi, M.; Hirakawa, A. Y.; Tamagake, K.; J. Mol. Spectrosc. 1967, 22, 272.
2. Takagi, K.; Kojima, T.; J. Phys. Soc. Jpn. 1971, 30, 1145.

3. Belorgeot, C.; Stern, V.; Goff, N.; Kachmarsky, J.; Möller, K. D.; J. Mol. Spectrosc. 1982, 92, 91.

4. Ijima, T.; Bull. Chem. Soc. Jpn. 1986, 59, 853.

5. Kreglewski, M.; J. Mol. Spectrosc. 1989, 133, 10.

6. Oda, M.; Ohashi, N.; Hougen, J. T.; J. Mol. Spectrosc. 1990, $142,57$.

7. Durig, J. R.; Zheng, C.; Struct. Chem. 2001, 12, 137.

8. Lee, S. J.; Mhin, B.J.; Cho, S. J.; Lee, J. Y.; Kim, K. S.; J. Phys. Chem. 1994, 98, 1129.

9. Csonka, G. I.; Sztraka, L.; Chem. Phys. Lett. 1995, 233, 611.

10. Smeyers, Y. G.; Villa, M.; Chem. Phys. Lett. 2000, 324, 273.

11. Pelegrini, M.; Roberto-Neto, O.; Machado, F. B. C.; Chem. Phys. Lett. 2005, 414, 495.

12. Levi, C.; Martin, J. M. L.; Bar, I.; J. Comput. Chem. 2008, 29 , 1268.

13. Kim, H.-W.; Zeroka, D.; Int. J. Quantum Chem. 2008, 108, 974.

14. Ducati, L. C.; Custodio, R.; Rittner, R.; Int. J. Quantum Chem. 2010, 110, 2006.

15. Beagley, B.; Hewitt, T. G.; Trans. Faraday Soc. 1968, 64, 2561.

16. Wollrab, J. E.; Laurie, V. W.; J. Chem. Phys. 1968, 48, 5058.

17. Wollrab, J. E.; Laurie, V. W.; J. Chem. Phys. 1971, 54, 532.

18. Durig, J. R.; Griffin, M. G.; Groner, P.; J. Phys. Chem. 1977, $81,554$.

19. Consalvo, D.; van Bladel, J. W. I.; Engeln, R.; Reuss, J.; Chem. Phys. 1993, 171, 221.

20. Skaarup, S.; Griffin, L. L.; Boggs, J. E.; J. Am. Chem. Soc. 1976, 98, 3140.

21. Senent, M. L.; Smeyers, Y. G.; J. Chem. Phys. 1996, 105, 2789.

22. Senent, M. L.; Smeyers, Y. G.; Moule, D. C.; Mol. Phys. 1998, 94, 949.

23. Senent, M. L.; Smeyers, Y. G.; J. Mol. Struct. (Theochem) 1999, $464,137$.

24. Lide Jr., D. R.; Mann, D. E.; J. Chem. Phys. 1958, 28, 572. 
25. Möller, K. D.; DeMeo, A. R.; Smith, D. R.; London, L. H.; J. Chem. Phys. 1967, 47, 2609.

26. Wollrab, J. E.; Laurie, V. W.; J. Chem. Phys. 1969, 51, 1580.

27. Durig, J. R.; Craven, S. M.; Bragin, J.; J. Chem. Phys. 1970, $53,38$.

28. Halpern, A. M.; Ondrechen, M. J.; Ziegler, L. D.; J. Am. Chem. Soc. 1986, 108, 3907.

29. Kölmel, C.; Ochsenfeld, C.; Ahlrichs, R.; Theor. Chim. Acta 1992, 82, 271.

30. Marsh, C. M. B.; Schaefer III, H. F.; J. Phys. Chem. 1995, 99 , 195.

31. Tanaka, M.; Aida, M.; Chem. Phys. Lett. 2006, 417, 316.

32. Martin, J. M. L.; Taylor, P. R.; Chem. Phys. Lett. 1995, 242, 343.

33. Martin, J. M. L.; Taylor, P. R.; Chem. Phys. Lett. 1996, 248, 336.

34. Becke, A. D.; J. Chem. Phys. 1993, 98, 5648.

35. Lee, C.; Yang, W.; Parr, R. G.; Phys. Rev. B 1988, 37, 785.

36. Dunning Jr., T. H.; J. Chem. Phys. 1989, 90, 1007.

37. González, C.; Schlegel, H. B.; J. Phys. Chem. 1990, 94, 5523.

38. Raghavachari, K.; Trucks, G. W.; Pople, J. A.; Head-Gordon, M.; Chem. Phys. Lett. 1989, 157, 479.

39. Halkier, A.; Helgaker, T.; Jørgensen, P.; Klopper, W.; Koch, H.; Olsen, J.; Wilson, A. K.; Chem. Phys. Lett. 1998, 286, 243.

40. Woon, D. E.; Dunning Jr., T. H.; J. Chem. Phys. 1995, 103, 4572.

41. Frisch, M. J.; Trucks, G. W.; Schlegel, H. B.; Scuseria, G. E.; Robb, M. A.; Cheeseman, J. R.; Montgomery, J. A.; Jr.; Vreven, T; Kudin, K. N.; Burant, J. C.; Millam, J. M.; Iyengar, S. S.;
Tomasi, J.; Barone, V.; Mennucci, B.; Cossi, M.; Scalmani, G.; Rega, N.; Petersson, G. A.; Nakatsuji, H.; Hada, M.; Ehara, M.; Toyota, K.; Fukuda, R.; Hasegawa, J.; Ishida, M.; Nakajima, T.; Honda, Y.; Kitao, O.; Nakai, H.; Klene, M.; Li, X.; Knox, J. E.; Hratchian, H. P.; Cross, J. P.; Adamo, C.; Jaramillo, J.; Gomperts, R.; Stratmann, R. E.; Yazyev, O.; Austin, A. J.; Cammi, R.; Pomelli, C.; Ochterski, J. W.; Ayala, P. Y.; Morokuma, K.; Voth, G. A.; Salvador, P.; Dannenberg, J. J.; Zakrzewski, V. G.; Dapprich, S.; Daniels, A. D.; Strain, M. C.; Farkas, O.; Malick, D. K.; Rabuck, A. D.; Raghavachari, K.; Foresman, J. B.; Ortiz, J. V.; Cui, Q.; Baboul, A. G.; Clifford, S.; Cioslowski, J.; Stefanov, B. B.; Liu, G.; Liashenko, A.; Piskorz, P.; Komaromi, I.; Martin, R. L.; Fox, D. J.; Keith, T.; Al-Laham, M. A.; Peng, C. Y.; Nanayakkara, A.; Challacombe, M.; Gill, P. M. W.; Johnson, B.; Chen, W.; Wong, M. W.; González, C.; Pople, J. A.; Gaussian 03, Revision D.01, Gaussian, Inc.: Wallingford CT, 2004.

42. Werner, H. -J.; Knowles, P. J.; Almlöf, J.; Amos, R. D.; Berning, A.; Cooper, D. L.; Deegan, M. J. O.; Dobbyn, A. J.; Eckert, F.; Elbert, S. T.; Hampel, C.; Lindh, R.; Lloyd, A. W.; Meyer, W.; Nicklass, A.; Peterson, K.; Pitzer, R.; Stone, A. J.; Taylor, P. R.; Mura, M. E.; Pulay, P.; Schütz, M.; Stoll, H.; Thorsteinsson, T.; MOLPRO, version 2002.6 a package of ab initio programs. 2002.

Submitted: July 13, 2010

Published online: February 10, 2011

FAPESP has sponsored the publication of this article. 


\title{
A Theoretical Study of the Inversion and Rotation Barriers in Methyl-Substituted Amines
}

\author{
Júnior Nascimento, ${ }^{a}$ Marina Pelegrini, ${ }^{c}$ Luiz F. A. Ferrão ${ }^{a, b}$ \\ Orlando Roberto-Neto ${ }^{d}$ and Francisco B. C. Machado*,a
}

${ }^{a}$ Departamento de Química and ${ }^{b}$ Departamento de Física, Instituto Tecnológico de Aeronáutica, 12228-900 São José dos Campos-SP, Brazil

'Divisão de Ensino, Academia da Força Aérea, 13643-000 Pirassununga-SP, Brazil

${ }^{d}$ Divisão de Aerotermodinâmica e Hipersônica, Instituto de Estudos Avançados, 12228-840 São José dos Campos-SP, Brazil

Table S1. Optimized geometries of methylamine. Bond distances (in $\AA$ ) and angle (in degrees)

\begin{tabular}{|l|l|}
\hline Ground state & Rotation transition state \\
\hline First order inversion transition state & Second order inversion transition state \\
\hline Ha
\end{tabular}

\begin{tabular}{|c|c|c|c|c|c|c|c|}
\hline \multicolumn{8}{|c|}{ Ground State } \\
\hline Method/Basis & $\mathrm{CN}$ & $\mathrm{NH}$ & $\mathrm{CHa}$ & $\mathrm{CH}$ & $\mathrm{NCHa}$ & $\mathrm{NCH}$ & $\mathrm{CNH}$ \\
\hline B3LYP/cc-pVQZ & 1.463 & 1.011 & 1.097 & 1.090 & 115.2 & 109.2 & 110.7 \\
\hline $\operatorname{CCSD}(\mathrm{T}) / \mathrm{cc}-\mathrm{pVTZ}$ (valence) & 1.469 & 1.014 & 1.097 & 1.091 & 115.1 & 109.1 & 109.2 \\
\hline $\operatorname{CCSD}(\mathrm{T}) / \mathrm{cc}-\mathrm{pVQZ}$ (valence) & 1.465 & 1.012 & 1.096 & 1.090 & 115.0 & 109.1 & 109.8 \\
\hline CCSD(T)-CBS (valence) & 1.462 & 1.011 & 1.095 & 1.089 & 114.9 & 109.1 & 110.2 \\
\hline CCSD(T)/cc-pCVTZ (valence) & 1.468 & 1.013 & 1.097 & 1.091 & 115.1 & 109.1 & 109.2 \\
\hline $\operatorname{CCSD}(\mathrm{T}) / \mathrm{cc}-\mathrm{pCVTZ}$ (full) & 1.466 & 1.012 & 1.096 & 1.090 & 115.1 & 109.1 & 109.4 \\
\hline CCSD $(\mathrm{T}) /($ equation 2$)$ & 1.460 & 1.010 & 1.094 & 1.088 & 114.9 & 109.1 & 110.4 \\
\hline \multicolumn{8}{|c|}{ Rotation transition state } \\
\hline B3LYP/cc-pVQZ & 1.468 & 1.009 & 1.092 & 1.091 & 110.9 & 112.0 & 111.6 \\
\hline $\operatorname{CCSD}(\mathrm{T}) / \mathrm{cc}-\mathrm{pVTZ}$ (valence) & 1.473 & 1.010 & 1.092 & 1.093 & 110.9 & 111.7 & 110.6 \\
\hline $\operatorname{CCSD}(\mathrm{T}) / \mathrm{cc}-\mathrm{pVQZ}$ (valence) & 1.469 & 1.008 & 1.091 & 1.091 & 110.8 & 111.7 & 111.1 \\
\hline $\operatorname{CCSD}(\mathrm{T})-\mathrm{CBS}$ (valence) & 1.466 & 1.008 & 1.090 & 1.090 & 110.7 & 111.7 & 111.4 \\
\hline CCSD(T)/cc-pCVTZ (valence) & 1.473 & 1.009 & 1.091 & 1.092 & 110.9 & 111.7 & 110.6 \\
\hline $\operatorname{CCSD}(\mathrm{T}) / \mathrm{cc}-\mathrm{pCVTZ}$ (full) & 1.470 & 1.008 & 1.090 & 1.091 & 111.0 & 111.7 & 110.7 \\
\hline $\operatorname{CCSD}(\mathrm{T}) /($ equation 2$)$ & 1.464 & 1.006 & 1.089 & 1.089 & 110.7 & 111.7 & 111.4 \\
\hline
\end{tabular}

*e-mail: fmachado@ita.br 
Table S1. Optimized geometries of methylamine. Bond distances (in Å) and angle (degree) (cont.)

\begin{tabular}{|c|c|c|c|c|c|c|c|}
\hline \multicolumn{8}{|c|}{ First order inversion transition state } \\
\hline B3LYP/cc-pVQZ & 1.437 & 0.997 & 1.089 & 1.096 & 109.1 & 113.2 & 121.2 \\
\hline $\operatorname{CCSD}(\mathrm{T}) / \mathrm{cc}-\mathrm{pVTZ}$ (valence) & 1.439 & 0.997 & 1.091 & 1.096 & 108.9 & 113.1 & 121.0 \\
\hline $\operatorname{CCSD}(\mathrm{T}) / \mathrm{cc}-\mathrm{pVQZ}$ (valence) & 1.438 & 0.996 & 1.089 & 1.095 & 109.0 & 112.9 & 121.1 \\
\hline $\operatorname{CCSD}(\mathrm{T})$-CBS (valence) & 1.437 & 0.995 & 1.088 & 1.094 & 109.1 & 112.8 & 121.2 \\
\hline $\operatorname{CCSD}(\mathrm{T}) / \mathrm{cc}-\mathrm{pCVTZ}$ (valence) & 1.438 & 0.997 & 1.091 & 1.096 & 108.9 & 113.1 & 121.0 \\
\hline CCSD(T) /cc-pCVTZ (full) & 1.437 & 0.996 & 1.089 & 1.095 & 109.0 & 113.1 & 121.2 \\
\hline $\operatorname{CCSD}(\mathrm{T}) /(\mathrm{Eq} .2)$ & 1.436 & 0.994 & 1.086 & 1.093 & 109.2 & 112.8 & 121.2 \\
\hline \multicolumn{8}{|c|}{ Second order inversion transition state } \\
\hline B3LYP/cc-pVQZ & 1.438 & 0.998 & 1.098 & 1.091 & 114.4 & 110.5 & 121.2 \\
\hline $\operatorname{CCSD}(\mathrm{T}) / \mathrm{cc}-\mathrm{pVTZ}$ (valence) & 1.439 & 0.997 & 1.098 & 1.093 & 114.0 & 110.6 & 121.0 \\
\hline $\operatorname{CCSD}(\mathrm{T}) / \mathrm{cc}-\mathrm{pVQZ}$ (valence) & 1.438 & 0.997 & 1.097 & 1.091 & 113.9 & 110.5 & 121.0 \\
\hline CCSD(T)-CBS (valence) & 1.437 & 0.996 & 1.095 & 1.091 & 113.7 & 110.4 & 121.0 \\
\hline $\operatorname{CCSD}(\mathrm{T}) / \mathrm{cc}-\mathrm{pCVTZ}$ (valence) & 1.439 & 0.997 & 1.098 & 1.092 & 114.0 & 110.5 & 121.0 \\
\hline CCSD(T) /cc-pCVTZ (full) & 1.437 & 0.996 & 1.097 & 1.091 & 114.0 & 110.5 & 121.0 \\
\hline $\operatorname{CCSD}(\mathrm{T}) /($ equation 2$)$ & 1.435 & 0.995 & 1.094 & 1.089 & 113.8 & 110.4 & 121.0 \\
\hline
\end{tabular}

Table S2. Optimized geometries of dimethylamine. Bond distances (in Å) and angle (degree)

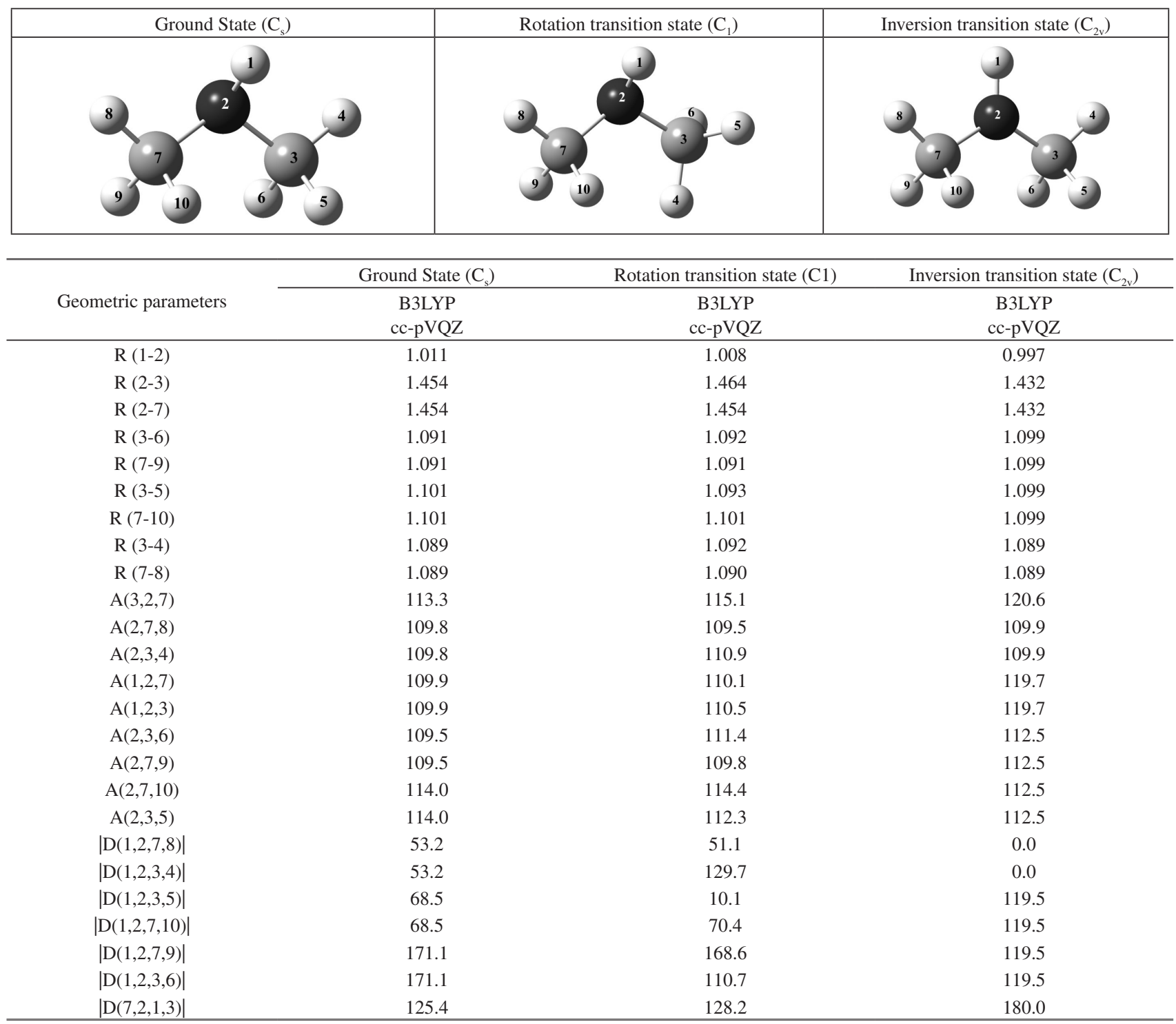


Table S3. Optimized geometries of trimethylamine. Bond distances (in $\AA$ ) and angle (degree)

Ground state $\left(\mathrm{C}_{3 \mathrm{v}}\right)$

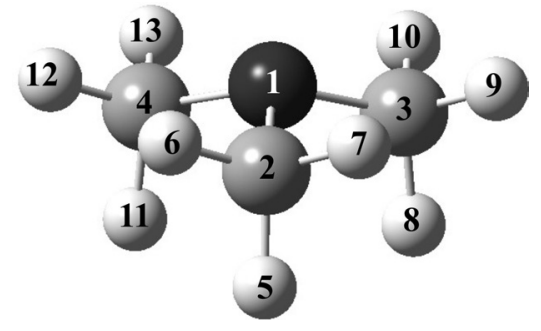

\begin{tabular}{lc}
\hline Geometric parameters & B3LYP/cc-pVQZ \\
\hline $\mathrm{R}(1,2) ; \mathrm{R}(1,3) ; \mathrm{R}(1,4)$ & 1.451 \\
$\mathrm{R}(2,6) ; \mathrm{R}(2,7) ; \mathrm{R}(3,9) ; \mathrm{R}(3,10) ; \mathrm{R}(4,12) ; \mathrm{R}(4,13)$ & 1.090 \\
$\mathrm{R}(2,5) ; \mathrm{R}(3,8) ; \mathrm{R}(4,11)$ & 1.104 \\
$\mathrm{~A}(2,1,3) ; \mathrm{A}(2,1,4) ; \mathrm{A}(3,1,4)$ & 111.8 \\
$\mathrm{~A}(1,2,5) ; \mathrm{A}(1,3,8) ; \mathrm{A}(1,4,11)$ & 112.9 \\
$\mathrm{~A}(6,2,7) ; \mathrm{A}(9,3,10) ; \mathrm{A}(12,4,13)$ & 108.1 \\
$\mathrm{~A}(1,2,6) ; \mathrm{A}(1,2,7) ; \mathrm{A}(1,3,9) ; \mathrm{A}(1,3,10) ; \mathrm{A}(1,4,12) ;$ & 109.9 \\
$\mathrm{~A}(1,4,13)$ & \\
$\mathrm{A}(5,2,6) ; \mathrm{A}(5,2,7) ; \mathrm{A}(8,3,9) ; \mathrm{A}(8,3,10) ; \mathrm{A}(11,4,12) ;$ & 108.0 \\
$\mathrm{~A}(11,4,13)$ &
\end{tabular}

Rotation transition state $\left(\mathrm{C}_{\mathrm{s}}\right)$

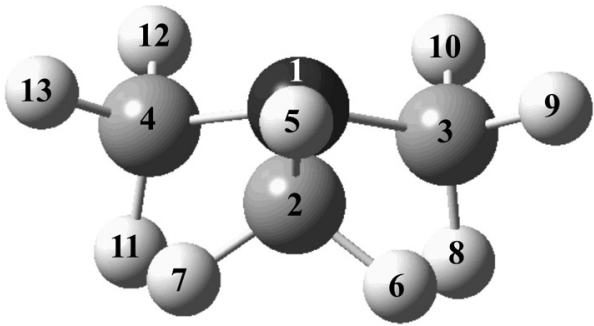

\begin{tabular}{lc}
\hline Geometric parameters & B3LYP/cc-pVQZ \\
\hline R $(1,2)$ & 1.464 \\
R $(1,3)(1,4)$ & 1.450 \\
R $(2,5)$ & 1.093 \\
R $(2,6)(2,7)$ & 1.092 \\
R $(3,8)(4,11)$ & 1.104 \\
R $(3,10)(4,12)$ & 1.090 \\
R $(3,9)(4,13)$ & 1.090 \\
A $(2,1,3)(2,1,4)$ & 113.3 \\
A $(3,1,4)$ & 112.4 \\
A $(1,2,6)(1,2,7)$ & 111.4 \\
A $(1,2,5)$ & 111.5 \\
A $(5,2,6)(5,2,7)$ & 107.7 \\
A $(6,2,7)$ & 106.8 \\
A $(1,3,8)(1,4,11)$ & 113.3 \\
A $(1,3,9)(1,4,13)$ & 109.8 \\
A $(1,3,10)(1,4,12)$ & 110.1 \\
A $(9,3,10)(12,4,13)$ & 107.7 \\
A $(11,4,13)(8,3,9)$ & 108.0 \\
A $(11,4,12)(8,3,10)$ & 107.8 \\
\hline
\end{tabular}

Inversion transition state $\left(\mathrm{C}_{\mathrm{s}}\right)$

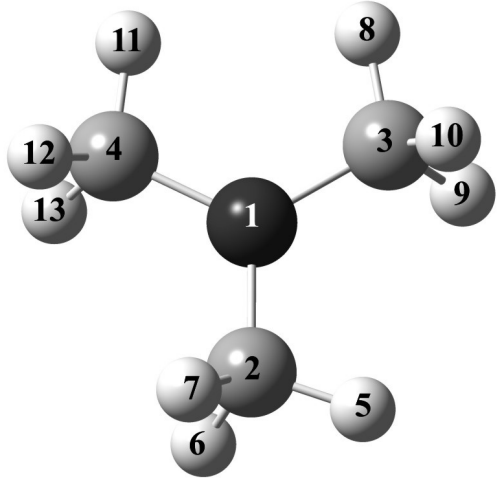

\begin{tabular}{lc}
\hline Geometric parameters & B3LYP/cc-pVQZ \\
\hline $\mathrm{R}(1,2)$ & 1.434 \\
$\mathrm{R}(1,4)$ & 1.434 \\
$\mathrm{R}(1,3)$ & 1.437 \\
$\mathrm{R}(2,6) ; \mathrm{R}(2,7) ; \mathrm{R}(4,13) ; \mathrm{R}(4,12)$ & 1.100 \\
$\mathrm{R}(3,9) ; \mathrm{R}(3,10)$ & 1.099 \\
$\mathrm{R}(2,5) ; \mathrm{R}(3,8) ; \mathrm{R}(4,11)$ & 1.089 \\
$\mathrm{~A}(2,1,4)$ & 117.3 \\
$\mathrm{~A}(3,1,4)$ & 122.8 \\
$\mathrm{~A}(2,1,3)$ & 120.0 \\
$\mathrm{~A}(1,2,6) ; \mathrm{A}(1,2,7)$ & 112.4 \\
$\mathrm{~A}(1,4,11)$ & 110.3 \\
$\mathrm{~A}(1,4,12) ; \mathrm{A}(1,4,13)$ & 112.4 \\
$\mathrm{~A}(1,2,5)$ & 110.1 \\
$\mathrm{~A}(1,3,10) ; \mathrm{A}(1,3,9)$ & 112.8 \\
$\mathrm{~A}(1,3,8)$ & 109.6 \\
$\mathrm{D}(3,1,4,11) ; \mathrm{D}(3,1,2,5)$ & 0.0 \\
\hline
\end{tabular}


Table S4. Vibrational frequencies $\left(\mathrm{cm}^{-1}\right)$ of methylamine

\begin{tabular}{lccc} 
Ground state & & & \\
\hline B3LYP/cc-pVQZ & 300 & 833 & 975 \\
1055 & 1173 & 1348 \\
1461 & 1499 & 1518 \\
& 1664 & 2965 & 3055 \\
\hline CCSD(T)/cc-pVTZ & 3089 & 3496 & 3570 \\
& 302 & 877 & 976 \\
& 1066 & 1187 & 1359 \\
& 1458 & 1508 & 1528 \\
& 1666 & 2997 & 3080 \\
& 3116 & 3499 & 3580 \\
\hline
\end{tabular}

Rotation transition state

\begin{tabular}{lccc}
\hline B3LYP/cc-pVQZ & $297 i$ & 799 & 993 \\
1053 & 1158 & 1327 \\
1464 & 1495 & 1522 \\
1665 & 3009 & 3049 \\
\hline CCSD(T)/cc-pVTZ & 3072 & 3532 & 3605 \\
& $350 i$ & 914 & 996 \\
& 1066 & 1166 & 1338 \\
& 1453 & 1485 & 1514 \\
& 1663 & 3025 & 3090 \\
& 3104 & 3496 & 3575 \\
\hline
\end{tabular}

First order inversion transition state

\begin{tabular}{lccc}
\hline B3LYP/cc-pVQZ & $672 \mathrm{i}$ & 101 & 921 \\
1114 & 1169 & 1287 \\
1472 & 1482 & 1535 \\
& 1636 & 2967 & 2986 \\
\hline $\mathrm{CCSD}(\mathrm{T}) / \mathrm{cc}-\mathrm{pVTZ}$ & 3085 & 3659 & 3779 \\
& $749 \mathrm{i}$ & 107 & 918 \\
& 1137 & 1174 & 1292 \\
& 1470 & 1493 & 1545 \\
& 1642 & 2993 & 3027 \\
& 3106 & 3700 & 3826 \\
\hline
\end{tabular}

Second order inversion transition state

\begin{tabular}{lccc}
\hline B3LYP/cc-pVQZ & $660 \mathrm{i}$ & $112 \mathrm{i}$ & 922 \\
1109 & 1170 & 1290 \\
1461 & 1502 & 1525 \\
& 1635 & 2948 & 3027 \\
$\mathrm{CCSD}(\mathrm{T}) / \mathrm{cc}-\mathrm{pVTZ}$ & 3065 & 3660 & 3778 \\
& $740 \mathrm{i}$ & $116 \mathrm{i}$ & 916 \\
& 1129 & 1178 & 1295 \\
& 1462 & 1508 & 1537 \\
& 1641 & 2981 & 3053 \\
& 3093 & 3701 & 3826 \\
\hline
\end{tabular}

Table S5. Vibrational frequencies $\left(\mathrm{cm}^{-1}\right)$ of dimethylamine

B3LYP/cc-pVQZ

\begin{tabular}{|c|c|c|c|}
\hline \multirow[t]{8}{*}{ Groundstate } & 230 & 258 & 381 \\
\hline & 761 & 938 & 1036 \\
\hline & 1102 & 1168 & 1187 \\
\hline & 1268 & 1443 & 1470 \\
\hline & 1477 & 1488 & 1495 \\
\hline & 1517 & 1518 & 2923 \\
\hline & 2926 & 3041 & 3041 \\
\hline & 3089 & 3089 & 3525 \\
\hline \multirow[t]{8}{*}{ Rotation transition state } & $253 \mathrm{i}$ & 236 & 391 \\
\hline & 699 & 926 & 1057 \\
\hline & 1106 & 1159 & 1187 \\
\hline & 1260 & 1446 & 1473 \\
\hline & 1481 & 1488 & 1497 \\
\hline & 1515 & 1522 & 2925 \\
\hline & 2998 & 3039 & 3042 \\
\hline & 3061 & 3086 & 3556 \\
\hline \multirow[t]{8}{*}{ Inversion transition state } & $591 \mathrm{i}$ & 180 & 183 \\
\hline & 381 & 944 & 1065 \\
\hline & 1143 & 1189 & 1232 \\
\hline & 1277 & 1453 & 1471 \\
\hline & 1473 & 1474 & 1480 \\
\hline & 1527 & 1540 & 2932 \\
\hline & 2943 & 2943 & 2953 \\
\hline & 3088 & 3089 & 3716 \\
\hline
\end{tabular}


Table S6. Vibrational frequencies $\left(\mathrm{cm}^{-1}\right)$ of trimethylamine

B3LYP/cc-pVQZ

\begin{tabular}{|c|c|c|c|}
\hline \multirow[t]{11}{*}{ Groundstate } & 252 & 265 & 265 \\
\hline & 357 & 422 & 422 \\
\hline & 830 & 1057 & 1057 \\
\hline & 1071 & 1121 & 1121 \\
\hline & 1208 & 1306 & 1306 \\
\hline & 1443 & 1443 & 1482 \\
\hline & 1482 & 1483 & 1490 \\
\hline & 1502 & 1511 & 1511 \\
\hline & 2894 & 2894 & 2908 \\
\hline & 3048 & 3048 & 3053 \\
\hline & 3089 & 3093 & 3093 \\
\hline \multirow[t]{11}{*}{ Rotation transition state } & $268 \mathrm{i}$ & 242 & 246 \\
\hline & 331 & 425 & 435 \\
\hline & 820 & 1049 & 1055 \\
\hline & 1081 & 1121 & 1131 \\
\hline & 1183 & 1305 & 1306 \\
\hline & 1445 & 1448 & 1484 \\
\hline & 1486 & 1491 & 1497 \\
\hline & 1501 & 1511 & 1513 \\
\hline & 2889 & 2897 & 2997 \\
\hline & 3041 & 3046 & 3051 \\
\hline & 3058 & 3088 & 3091 \\
\hline \multirow[t]{11}{*}{ Inversion transition state } & $300 \mathrm{i}$ & 95 & 108 \\
\hline & 134 & 384 & 433 \\
\hline & 808 & 1074 & 1093 \\
\hline & 1106 & 1122 & 1153 \\
\hline & 1170 & 1331 & 1391 \\
\hline & 1447 & 1458 & 1469 \\
\hline & 1472 & 1484 & 1500 \\
\hline & 1514 & 1528 & 1541 \\
\hline & 2922 & 2927 & 2930 \\
\hline & 2945 & 2947 & 2949 \\
\hline & 3086 & 3090 & 3098 \\
\hline
\end{tabular}

